OPEN ACCESS

Approved by:

Frontiers in Psychology,

Frontiers Media SA, Switzerland

*Correspondence:

Krystyna Kowalczuk

krystyna.kowalczuk@umb.edu.pl

Specialty section:

This article was submitted to

Organizational Psychology,

a section of the journal

Frontiers in Psychology

Received: 17 December 2018 Accepted: 20 December 2018

Published: 10 January 2019

Citation:

Kowalczuk K, Krajewska-Kułak E and Sobolewski M (2019) Corrigendum:

Psychosocial Hazards in the Workplace as an Aspect of Horizontal Segregation in the Nursing Profession.

Front. Psychol. 9:2753.

doi: 10.3389/fpsyg.2018.02753

\section{Corrigendum: Psychosocial Hazards in the Workplace as an Aspect of Horizontal Segregation in the Nursing Profession}

\author{
Krystyna Kowalczuk ${ }^{1 *}$, Elżbieta Krajewska-Kułak ${ }^{1}$ and Marek Sobolewski ${ }^{2}$ \\ ${ }^{1}$ Medical University of Bialystok, Bialystok, Poland, ${ }^{2}$ Rzeszów University of Technology, Rzeszow, Poland
}

Keywords: gender, psychosocial aspects of work, male nurse, nurse, feminized profession, psychosocial hazards

\section{A Corrigendum on}

Psychosocial Hazards in the Workplace as an Aspect of Horizontal Segregation in the Nursing Profession

by Kowalczuk, K., Krajewska-Kułak, E., and Sobolewski, M. (2018). Front. Psychol. 9:2042. doi: 10.3389/fpsyg.2018.02042

In the published article, there was an error in affiliation of the second author, Elzbieta KrajewskaKułak. Instead of affiliation "2," it should be affiliation " 1. "

The authors apologize for this error and state that this does not change the scientific conclusions of the article in any way. The original article has been updated.

Conflict of Interest Statement: The authors declare that the research was conducted in the absence of any commercial or financial relationships that could be construed as a potential conflict of interest.

Copyright $\odot 2019$ Kowalczuk, Krajewska-Kulak and Sobolewski. This is an open-access article distributed under the terms of the Creative Commons Attribution License (CC BY). The use, distribution or reproduction in other forums is permitted, provided the original author(s) and the copyright owner(s) are credited and that the original publication in this journal is cited, in accordance with accepted academic practice. No use, distribution or reproduction is permitted which does not comply with these terms. 